\title{
Erratum to: Cancer chemoprevention through dietary flavonoids: what's limiting?
}

\author{
Haneen Amawi ${ }^{1}$, Charles R. Ashby Jr. ${ }^{2}$ and Amit K. Tiwari ${ }^{1,3^{*}}$
}

\section{Erratum to: Chin J Cancer (2017) 36:50 DOI 10.1186/s40880-017-0217}

After publication of the original article [1], it is noticed that the cited author list and Google Scholar link in Reference 184 are not correct. Revised Reference 184 is as follows:

"184. Khan MA, Rankin SE, Littleton JM and Knutson BL. 471914 nanoharvesting of polyphenolic flavonoids from solidago nemoralis hairy root cultures using functionalized mesoporous silica nanoparticles. 2016 AIChE annual meeting 2016. San Francisco: American Institute of Chemical Engineers; 2016.

https://scholar.google.com/citations?view_op=view_cita tion\&hl=en\&user $=$ F4lbzUkAAAAJ\&citation_for_view $=$ F4lbzUkAAAAJ:geHnlv5EZngC".

\begin{abstract}
Author details
${ }^{1}$ Department of Pharmacology and Systems Therapeutics, College of Pharmacy and Pharmaceutical Sciences, University of Toledo, Toledo, $\mathrm{OH} 43560$, USA. ${ }^{2}$ Pharmaceutical Sciences, College of Pharmacy, St. John's University, Queens, NY 11432, USA. ${ }^{3}$ Department of Pharmacology and Experimental Therapeutics, College of Pharmacy and Pharmaceutical Sciences, University of Toledo, Toledo, $\mathrm{OH} 43614$, USA.
\end{abstract}

The online version of the original article can be found under doi:10.1186/s40880-017-0217-4.

Received: 24 August 2017 Accepted: 24 August 2017

Published online: 30 August 2017

\section{Reference}

1. Amawi H, Ashby CR, Tiwari AK. Cancer chemoprevention through dietary flavonoids: what's limiting? Chin J Cancer. 2017:36:50. doi:10.1186/ s40880-017-0217-4

\footnotetext{
*Correspondence: amit.tiwari@utoledo.edu

${ }^{3}$ Department of Pharmacology and Experimental Therapeutics, College of Pharmacy and Pharmaceutical Sciences, University of Toledo, Toledo, $\mathrm{OH}$ 43614, USA

Full list of author information is available at the end of the article
} provided you give appropriate credit to the original author(s) and the source, provide a link to the Creative Commons license, and indicate if changes were made. The Creative Commons Public Domain Dedication waiver (http://creativecommons.org/ publicdomain/zero/1.0/) applies to the data made available in this article, unless otherwise stated. 